\title{
Uterine sensitization-associated gene-1 (USAG-1), a novel BMP antagonist expressed in the kidney, accelerates tubular injury
}

\author{
Motoko Yanagita, ${ }^{1}$ Tomohiko Okuda, ${ }^{1}$ Shuichiro Endo, ${ }^{2}$ Mari Tanaka, ${ }^{2}$ Katsu Takahashi, ${ }^{3}$ \\ Fumihiro Sugiyama, ${ }^{4}$ Satoshi Kunita, ${ }^{4}$ Satoru Takahashi, ${ }^{4}$ Atsushi Fukatsu, ${ }^{5}$ \\ Masashi Yanagisawa, ${ }^{6,7}$ Toru Kita, ${ }^{2}$ and Takeshi Sakurai ${ }^{6,8}$
}

\begin{abstract}
${ }^{1} \mathrm{COE}$ Formation for Genomic Analysis of Disease Model Animals with Multiple Genetic Alterations, ${ }^{2}$ Department of Cardiovascular Medicine, and ${ }^{3}$ Department of Oral and Maxillofacial Surgery, Graduate School of Medicine, Kyoto University, Kyoto, Japan. ${ }^{4}$ Laboratory Animal Resource Center, Institute of Basic Medical Sciences, University of Tsukuba, Ibaraki, Japan. ${ }^{5}$ Department of Artificial Kidneys, Graduate School of Medicine, Kyoto University, Kyoto, Japan. ${ }^{6}$ Yanagisawa Orphan Receptor Project, Exploratory Research for Advanced Technology (ERATO), Japan Science and Technology Agency, Tokyo, Japan. ${ }^{7}$ Howard Hughes Medical Institute and Department of Molecular Genetics, University of Texas Southwestern Medical Center, Dallas, Texas, USA. ${ }^{8}$ Department of Pharmacology, Institute of Basic Medical Sciences, University of Tsukuba, Ibaraki, Japan.
\end{abstract}

\begin{abstract}
Dialysis dependency is one of the leading causes of morbidity and mortality in the world, and once endstage renal disease develops, it cannot be reversed by currently available therapy. Although administration of large doses of bone morphogenetic protein-7 (BMP-7) has been shown to repair established renal injury and improve renal function, the pathophysiological role of endogenous BMP-7 and regulatory mechanism of its activities remain elusive. Here we show that the product of uterine sensitization-associated gene-1 (USAG1), a novel BMP antagonist abundantly expressed in the kidney, is the central negative regulator of BMP function in the kidney and that mice lacking USAG-1 (USAG1 ${ }^{-/-}$mice) are resistant to renal injury. USAG1 ${ }^{-/-}$mice exhibited prolonged survival and preserved renal function in acute and chronic renal injury models. Renal BMP signaling, assessed by phosphorylation of Smad proteins, was significantly enhanced in USAG1 ${ }^{-/-}$mice with renal injury, indicating that the preservation of renal function is attributable to enhancement of endogenous BMP signaling. Furthermore, the administration of neutralizing antibody against BMP-7 abolished renoprotection in $U S A G 1^{-/}$mice, indicating that USAG-1 plays a critical role in the modulation of renoprotective action of BMP and that inhibition of USAG-1 is a promising means of development of novel treatment for renal diseases.
\end{abstract}

\section{Introduction}

Despite a significant increase in understanding of the pathophysiology of renal diseases, the incidence of end-stage renal disease (ESRD) is still increasing. Tubular damage and interstitial fibrosis are the final common pathway leading to $\operatorname{ESRD}(1,2)$, irrespective of the nature of the initial renal injury, and the degree of tubular damage parallels the impairment of renal function (2). Once tubular damage is established, it cannot be reversed or repaired by currently available treatment, and renal function deteriorates to renal failure, which is often life threatening (3). If we can come up with an agent that can reverse established tubular damage, it would significantly reduce the need for dialysis. Bone morphogenetic protein-7 (BMP-7) is a promising candidate for such an agent, because it is reported to protect the kidney from renal injury (4-8). BMP-7 is known to play essential roles in kidney development, because BMP-7-null mice die shortly after birth due to severe renal hypoplasia $(9,10)$. BMP-7 is also abundant in the adult kidney, especially in distal tubule epithelial cells $(11,12)$. Recently, several reports indicated that the expression of BMP-7 is decreased in renal dis-

Nonstandard abbreviations used: BMP-7, bone morphogenetic protein-7; EMT, epithelial-mesenchymal transition; MCP-1, monocyte chemotactic protein-1; PTEC, proximal tubule epithelial cell; USAG1, uterine sensitization-associated gene-1; UUO, unilateral ureteral obstruction.

Conflict of interest: The authors have declared that no conflict of interest exists.

Citation for this article: J. Clin. Invest. 116:70-79 (2006).

doi:10.1172/JCI25445. ease models $(5,6,13-16)$ and that administration of recombinant BMP-7 at pharmacological doses repairs chronic renal injury (4-8). However, the pathophysiological role and regulatory mechanism of endogenous BMP-7 remain elusive.

The local activity of endogenous BMP is controlled not only by regulation of its expression, but also by certain classes of molecules termed BMP antagonists (17). BMP antagonists function through direct association with BMP, thus inhibiting the binding of BMP to its receptors. Uterine sensitization-associated gene-1 (USAG1) encodes a secreted protein and was initially found as a gene of unknown function whose expression was upregulated in sensitized endometrium of the rat uterus (18). Recently, AvsianKretchmer et al. suggested USAG-1 as a candidate for a novel BMP antagonist using bioinformatic analysis (19). Furthermore, Laurikkala et al. demonstrated USAG-1 to be a BMP antagonist expressed in teeth (20).

We independently identified USAG-1 to be a novel BMP antagonist, abundantly expressed in the kidney (21). The expression of USAG- 1 is abundant in renal tubules and teeth in late embryogenesis and in adult tissues it is by far most abundant in the kidney, especially in the distal tubule with a pattern similar to that of BMP-7. From these findings, we hypothesized that USAG-1 might regulate the renoprotective action of BMP-7 in the adult kidney.

To evaluate this hypothesis, we generated USAG1-knockout $\left(U S A G 1^{--}\right)$mice and induced acute and chronic renal disease models in which renal tubules, but not glomeruli, were mainly damaged. 
A

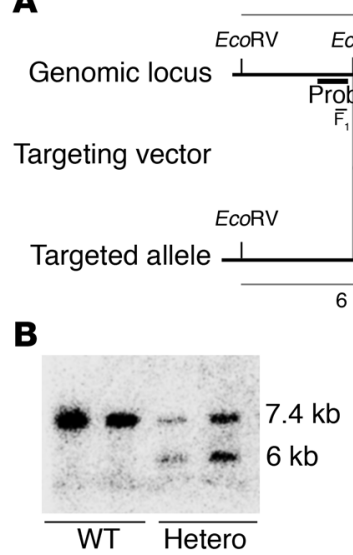

$7.4 \mathrm{~kb}$

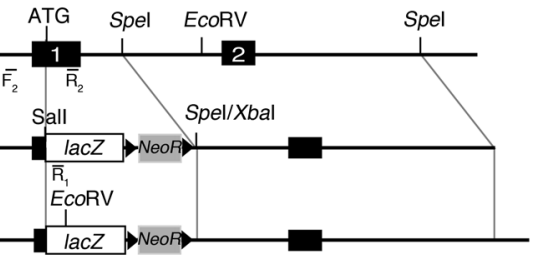

C

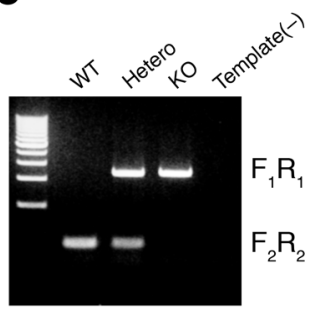

D

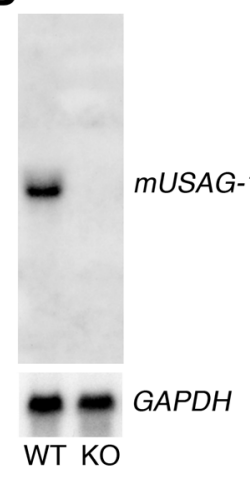

\section{Figure 1}

Generation of USAG1-/- mutation by gene targeting. (A) USAG1-null allele was generated by homologous recombination in ES cells. Exon 1 (black box) and part of the intron were replaced with a lac $Z$ gene (white box) and the NeoR cassette (gray box). (B) Analysis of USAG1+/+ (WT) and correctly targeted heterozygous (Hetero) ES cell clones by Southern blot analysis using $5^{\prime}$ genomic probe (thick black line in A). (C) PCR genotyping of $F_{2}$ littermates. Template $(-)$ is the negative control. (D) Northern blot analysis of USAG1 mRNA in the kidney of $U S A G 1^{+/+}$and $U S A G 1^{-/-}(\mathrm{KO})$ mice.

expression (Figure 2G). Expression of BMP-7 was comparable between wild-type mice and USAG1 $1^{-/-}$mice before and after injection of cisplatin (Figure 2G).

Renal fibrosis is reduced in USAG1 $1^{-1-}$ mice. As a model of chronic renal injury, we performed unilateral ureteral obstruction (UUO) $(26,27)$ in both $U S A G 1^{-/-}$mice and wild-type mice, and the kidneys were harvested 14 days after the operation. In wild-type mice, the obstructed kidney showed dilatation/degeneration of renal tubules and interstitial fibrosis, whereas the normal architecture was preserved in USAG1 ${ }^{-/-}$mice, except for mild dilatation of tubules (Figure 3, A and B). Expression of E-cadherin

\section{Results}

Generation and analysis of USAG1 $1^{-/-}$mice. USAG1 $1^{-/-}$mice were generated by deleting the first exon including the transcription initiation codon, the signal peptide, and the following 46 amino acids (Figure 1). USAG1 $1^{-1-}$ mice were born at the ratio expected according to Mendel's law of heredity and were viable, fertile, and appeared healthy except that they exhibited supernumerary teeth, both in the incisors and molars, and fused teeth in the molar region (Supplemental Figure 1; supplemental material available online with this article; doi:10.1172/JCI25445DS1). Although there was variation in the sites of extra teeth and fused teeth, this tooth phenotype was fully penetrant. Food consumption was not disturbed by this tooth phenotype in USAG1 $1^{-/-}$mice (data not shown).

Attenuated acute tubular injury in USAG1 $1^{-/-}$mice. To induce acute tubular injury, we utilized a cisplatin nephrotoxicity model (22-24). Administration of a nephrotoxic agent, cisplatin, to wild-type littermates caused acute tubular injury that resulted in severe renal failure. Within the first 3 days, $54 \%$ of wild-type mice died, while $92 \%$ of $U S A G 1^{-1-}$ mice survived the period (Figure $2 \mathrm{~A}$ ). The renal function of USAG1-/- mice on day 3 was significantly preserved compared with that in wild-type littermates (Figure 2B). Histological examination of the kidneys of wild-type mice on day 3 showed severe proximal tubular damage, while this change was markedly reduced in USAG1 $1^{-/}$mice (Figure 2, C and D). Expression of E-cadherin, a marker for tubular epithelial integrity (25), was markedly reduced in the kidneys of wild-type mice, while its expression was preserved in $U S A G 1^{-1-}$ mice (Figure 2E). Tubular apoptosis, a characteristic feature of tubular injury in cisplatin nephrotoxicity (23), was also significantly reduced in USAG1 $1^{-/-}$mice (Figure $2 \mathrm{~F}$ ). As reported previously (24), cisplatin administration resulted in upregulation of TNF- $\alpha$, IL-1 $\beta$, monocyte chemotactic protein-1 (MCP-1), TGF- $\beta 1$, and type IV collagen expression in the kidney of wild-type mice. However, the induction of these genes was completely abolished in $U S A G 1^{-1-}$ mice (Figure $2 \mathrm{G}$ ). Infiltration of macrophages and monocytes in the kidney was also significantly reduced in USAG1-/mice (Figure $2 \mathrm{H}$ ), in accordance with the reduction of MCP-1 was markedly reduced in the kidneys of wild-type mice, while its expression was preserved in $U S A G 1^{-/-}$mice (Figure 3C). Furthermore, expression of $\alpha$-SMA, a marker of tubulointerstitial myofibroblasts (28), was upregulated in the interstitium of the obstructed kidney of wild-type mice, while high expression of $\alpha$-SMA was restricted to vascular smooth muscle cells in USAG1-/mice (Figure 3D). Since expansion and fibrosis of the renal interstitium is another characteristic feature of UUO (6), we examined the deposition of type IV collagen, which is a normal component of the tubular basement membrane. The basement membranes of neighboring tubules are adjacent to each other in the normal kidney. In the obstructed kidney of wild-type mice, expansion of the interstitial component increased the distance between adjacent basement membranes, and type IV collagen produced by interstitial myofibroblasts was aberrantly expressed in the interstitium. However, in the obstructed kidney of USAG1 $1^{-/-}$mice, the distance between the basement membranes was significantly smaller than that in wild-type mice (Figure 3E). Expression of TNF- $\alpha$, IL-1 $\beta$, MCP-1, TGF- $\beta 1$, and type IV collagen was markedly upregulated on day 14 in the obstructed kidney of wild-type mice. In contrast, the induction of these genes was significantly attenuated, by $33 \%$, $46 \%, 37 \%, 75 \%$, and $23 \%$, respectively, in $U S A G 1^{-/-}$mice (Figure $3 \mathrm{~F}$ ). Expression of BMP-7 in the obstructed kidney was comparable in wild-type mice and $U S A G 1^{-1-}$ mice.

$B M P$ signaling is enhanced in USAG1 $1^{-/-}$mice. To evaluate whether the reduction in renal injury in USAG1 $1^{-/}$mice is attributable to enhanced BMP signaling, phosphorylation of Smad1/5/8 in the kidney was examined in both models (Figure 4). After the induction of kidney disease models, phosphorylation of Smad1/5/8 was hardly detected in wild-type mice, while in USAG1-/-mice, the phosphorylation was preserved in the nuclei of tubular epithelial cells (Figure 4A). To examine the specificity of the antibody against phospho-Smad $1 / 5 / 8$, we performed double immunostaining using anti-phospho-Smad1/5/8 antibody and anti-phospho-Smad2/3, and found that most of the nuclei positive for phospho-Smad1/5/8 were negative for phospho-Smad2/3 (Figure 4B), indicating the 

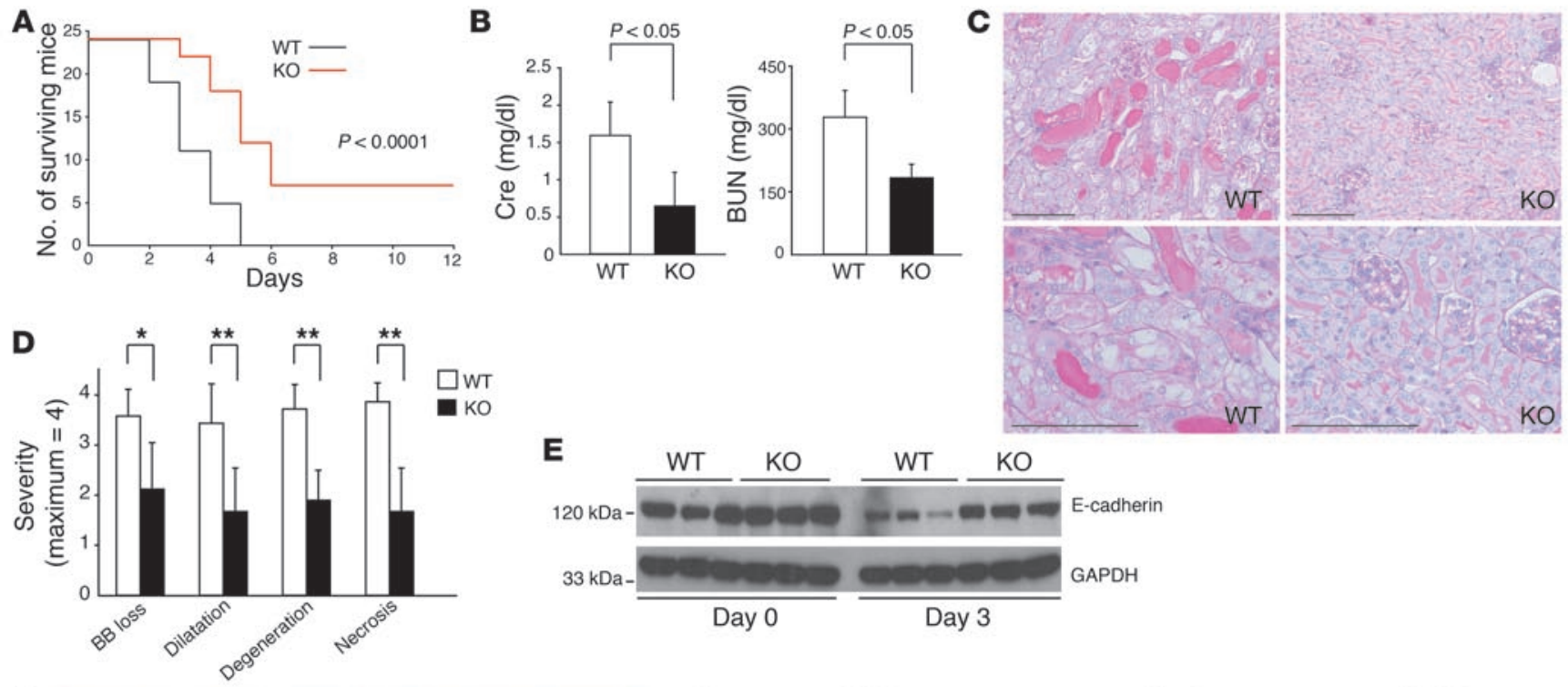

$\mathbf{F}$
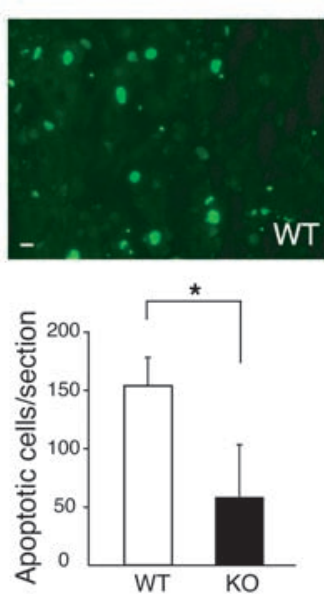

H
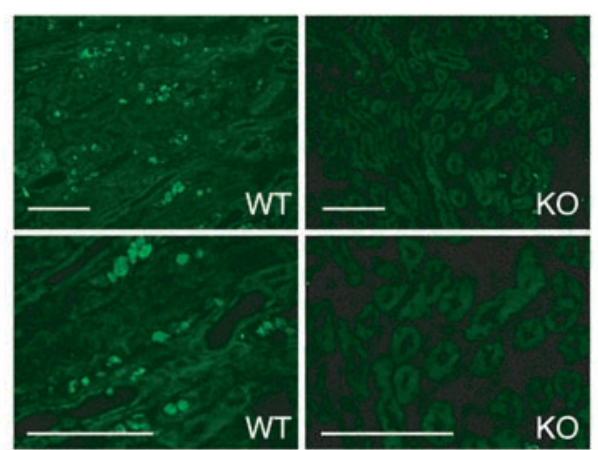
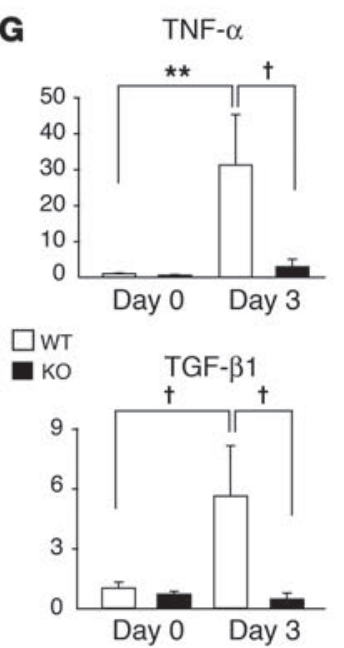
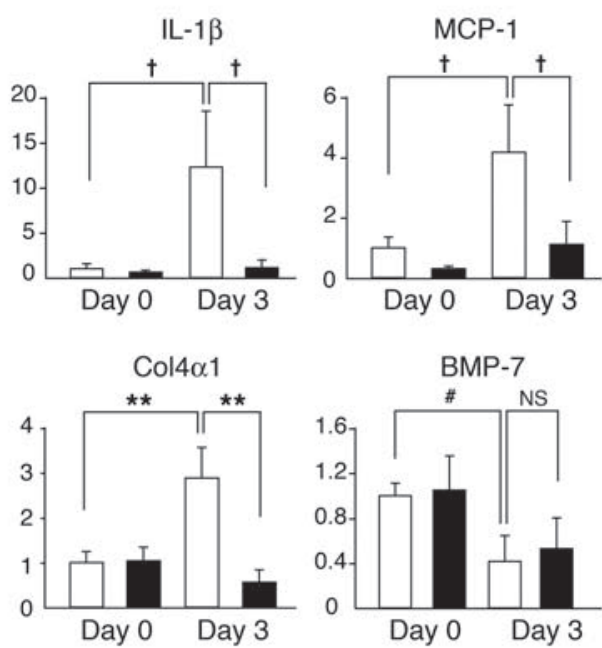

Figure 2

USAG1-/- mice showed less renal injury in cisplatin nephrotoxicity. (A) Survival curves of wild-type mice (black line) and USAG1-/- mice (red line) after cisplatin administration $(n=24)$. (B) Serum creatinine (Cre) and blood urea nitrogen (BUN) levels at 3 days after injection of cisplatin $(n=6)$. (C) Representative renal histological findings in wild-type mice and USAG1-/ mice on day 3. Scale bars: $100 \mu \mathrm{m}$. (D) Semiquantitative evaluation of morphologic kidney damage, expressed as relative severity on a scale from 0 to $4(n=6)$. Morphological findings were scored according to proximal tubule brush border loss (BB loss), tubule dilatation (Dilatation), tubule degeneration (Degeneration), and tubule necrosis (Necrosis). ${ }^{*}<<0.01$; ${ }^{* *} P<0.001$. (E) E-cadherin expression in cisplatin nephrotoxicity. Kidney lysates were subjected to immunoblotting with anti-E-cadherin antibody. Representative data from 4 independent experiments are shown. (F) TUNEL staining of kidneys on day 3 of cisplatin nephrotoxicity. The number of TUNEL-positive cells per section was counted in transverse sections $(n=6)$. Scale bars: $10 \mu \mathrm{m}$. (G) Gene expression in cisplatin nephrotoxicity. Gene expression was determined by real-time RT-PCR. In each experiment, expression levels were normalized to the expression of GAPDH and expressed relative to mice on day $0 . n=4-6$ for each experiment. ${ }^{\dagger} P<0.005$; $\# P<0.02$. Col4 $\alpha 1$, collagen type IV $\alpha$ 1. (H) Infiltration of Mac-1-positive cells after cisplatin injection. The number of Mac-1-positive cells per field was counted in 10 consecutive fields $(n=6)$. Scale bars: 100 $\mu \mathrm{m}$. 
A
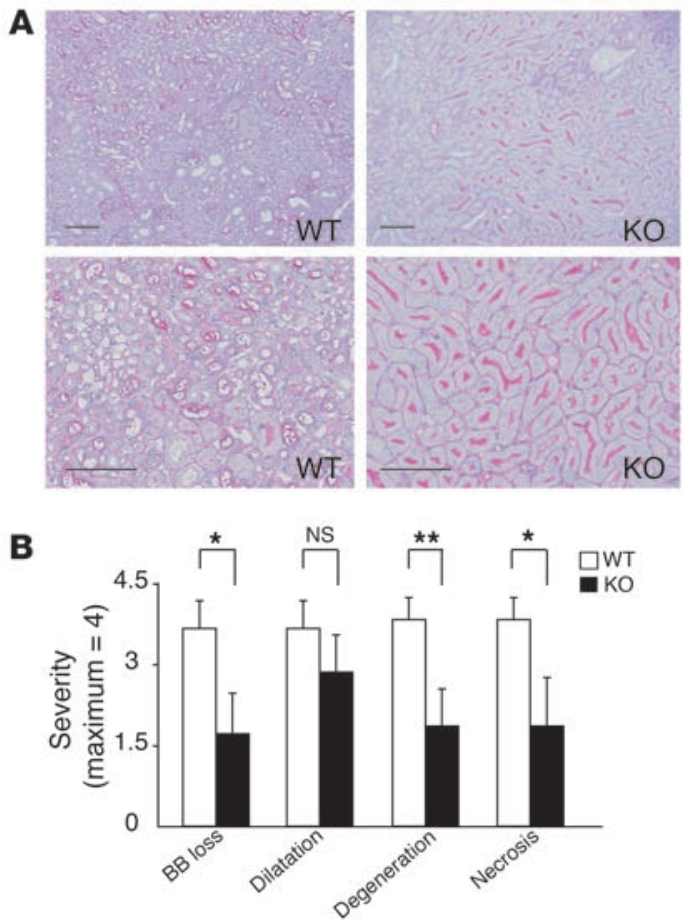

C

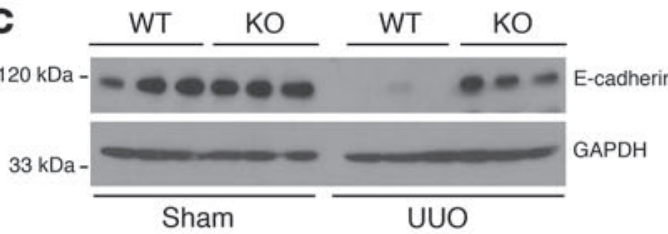

D

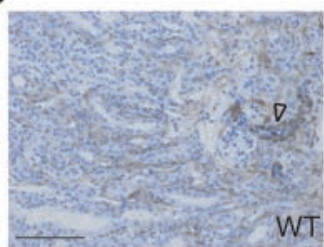

E

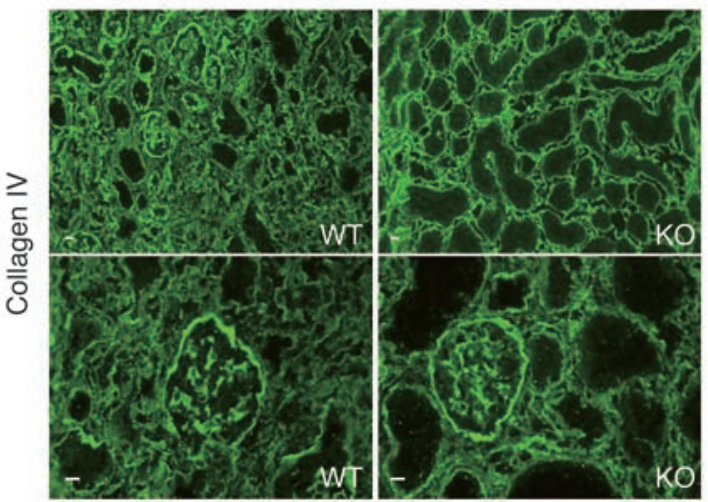

$\mathbf{F}$
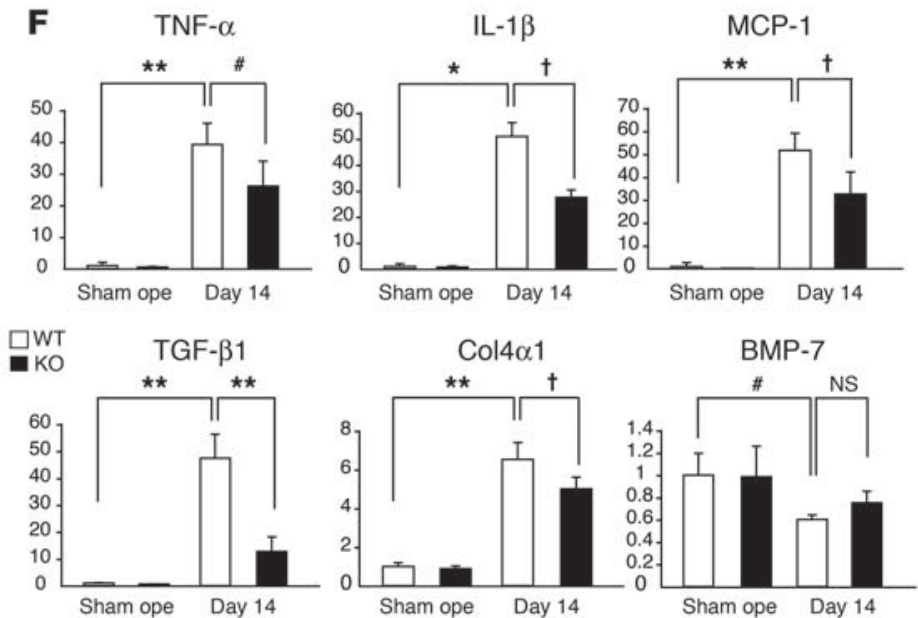

BMP-7
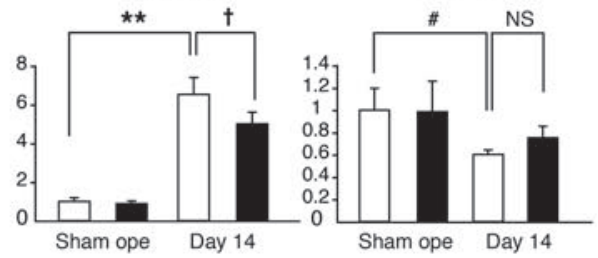

\section{Figure 3}

USAG1-1- mice showed reduced EMT and tubulointerstitial fibrosis in UUO. (A) Representative histology of the obstructed kidney in wild-type mice and USAG1 ${ }^{-1-}$ mice 14 days after the operation. Scale bars: $100 \mu \mathrm{m}$. (B) Semiquantitative evaluation of morphologic kidney damage in wild-type mice and USAG1-l- mice, expressed as relative severity on a scale from 0 to $4(n=6)$. (C) E-cadherin expression in UUO. Kidney lysates were subjected to immunoblotting with anti-E-cadherin antibody. Representative data from 4 independent experiments are shown. (D) Immunostaining of $\alpha$-SMA in UUO. Arrowheads indicate vascular smooth muscle cells. (E) Immunostaining of type IV collagen in UUO. Scale bars: $10 \mu \mathrm{m}$. (F) Gene expression in UUO. Gene expression was determined by real-time RT-PCR. In each experiment, the expression levels were normalized to the expression of GAPDH and expressed relative to expression in mice on day $0 . n=4-6$ for each experiment. $\# P<0.01$; ${ }^{\dagger} P<0.005 ;{ }^{\star} P<0.001 ;{ }^{*} P<0.0001$. Sham ope, mice 14 days after sham operation; day 14 , mice 14 days after UUO.

specificity of the antibody against phospho-Smad1/5/8. We also examined the phosphorylation of Smad1/5/8 in immunoblotting of kidney lysates and demonstrated that the phosphorylation was preserved in the kidneys of $U S A G 1^{-/-}$mice, while it was downregulated in WT mice (Figure 4C). No difference was observed in the phosphorylation of Smad $1 / 5 / 8$ prior to disease induction between USAG1 $1^{-1-}$ mice and WT mice (Figure 4, A and C).

Blocking BMP-7 activity abolishes renoprotection in USAG1-/-mice. To analyze the mechanism of renoprotection in USAG1/-mice, we administered a neutralizing antibody against BMP-7 to USAG1/mice in both kidney disease models. First we evaluated the speci- ficity of the neutralizing activity of the antibody using an assay measuring alkaline phosphatase activity and phosphorylation of Smad1/5/8 in C2C12 cells induced by BMPs. Addition of the antibody inhibited the alkaline phosphatase activity and phosphorylation of Smad1/5/8 induced by BMP-7, but not by BMP-4 (Figure $5 \mathrm{~A}$ ) or BMP-2 (data not shown), indicating the specificity of the antibody. As a negative control, we used isotype-matched IgG2B. Next we administered a neutralizing antibody against BMP-7 to USAG1 $1^{-/}$mice with cisplatin nephrotoxicity. Of 7 mice treated with neutralizing antibody, 2 mice died on day 2 and 1 mouse died on day 3 , while none of the mice treated with isotype-matched $\operatorname{IgG} 2 \mathrm{~B}$ 
A

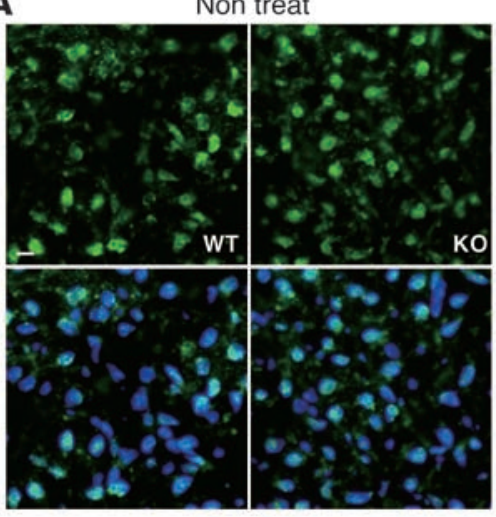

Cisplatin nephrotoxicity

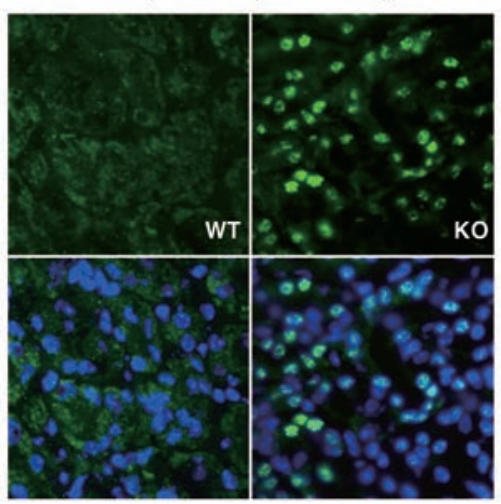

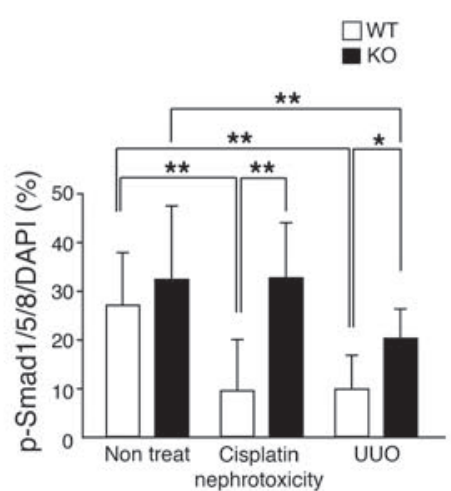

UUO

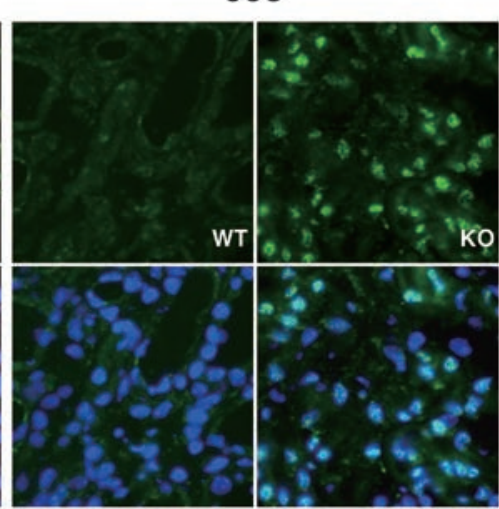

B

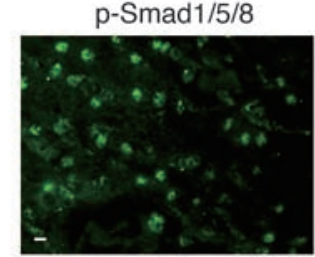

$\mathrm{p}-\mathrm{Smad} 2 / 3$

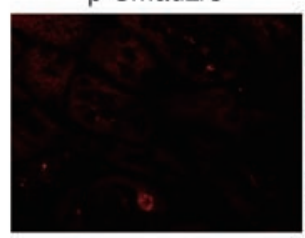

Overlay

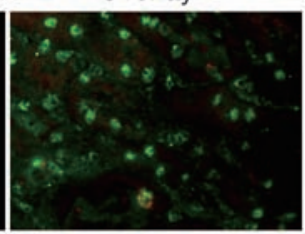

C $\mathrm{kDa}$
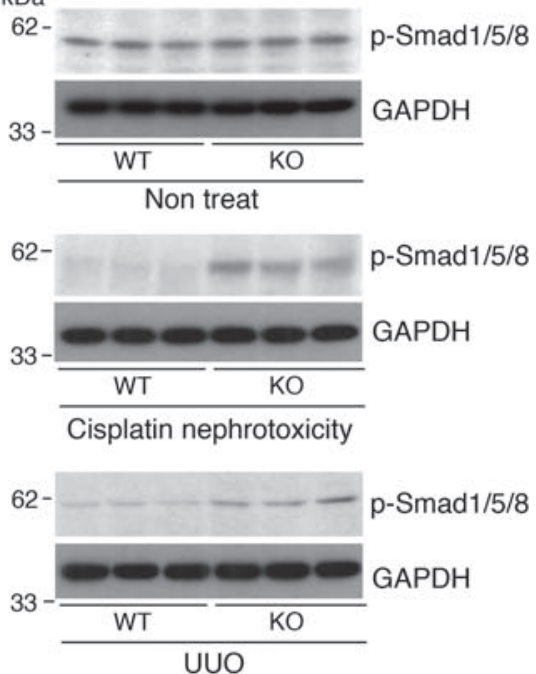

Figure 4

Enhanced BMP signaling in kidneys of USAG1-/- mice. (A) Phosphorylation of Smad1/5/8 in kidneys of USAG1 ${ }^{-/-}$mice and WT mice. The number of pSmad1/5/8-positive nuclei (upper panels) was counted in 10 consecutive fields in each specimen and normalized by the number of DAPI-positive nuclei (lower panels). $n=6$. Scale bar: $10 \mu \mathrm{m}$. ${ }^{\star} P<0.001$; ${ }^{\star \star} P<0.0001$. Non treat, mice without disease models. (B) Double immunostaining of phospho-Smad1/5/8 and phospho-Smad2/3. Almost all the nuclei positive for pSmad1/5/8 were negative for pSmad2/3. Scale bar: $10 \mathrm{um}$. (C) Immunoblotting of phospho-Smad1/5/8 in kidney lysates prior to disease induction and in both kidney disease models. Representative data from 5 independent experiments are shown.

died within the first 3 days. Administration of neutralizing antibody also resulted in a deterioration of renal function measured by elevation of serum creatinine to a level similar to that in WT mice, while administration of IgG2B did not (Figure 5B). Furthermore, histological examination of the kidneys of USAG1 $1^{-/-}$mice treated with neutralizing antibody demonstrated severely damaged proximal tubular epithelial cells, while these changes were absent in mice treated with IgG2B (Figure 5B). We also administered the neutralizing antibody to USAG1 $1^{-/-}$mice with UUO and found that type IV collagen expression in the obstructed kidney was increased in USAG1 $1^{-/-}$mice treated with neutralizing antibody, but not in those administered IgG2B (Figure 5C). Histological examination of the obstructed kidneys of USAG1/-- mice treated with neutralizing antibody demonstrated severe interstitial fibrosis, while this change was almost absent in mice treated with IgG2B (Figure 5C).

USAG1 is the most abundant BMP antagonist in adult kidney. Finally we analyzed the expression of USAG-1 and other BMP antagonists in adult kidneys using modified real-time PCR and in situ hybridization (Figure 6). To compare the expression levels of different genes in real-time PCR, we set the standard curve with the plasmid encoding each BMP antagonist at various concentrations and analyzed the copy number of each gene contained in kidney cDNA. Among known BMP antagonists, USAG-1 was by far the most abundant in the kidneys, and twisted gastrulation was the second most abundant BMP antagonist. We also analyzed the localization of BMP antagonists in the kidneys using in situ hybridization and found that the expression of USAG-1 was confined to distal tubules, as previously described (21), with a pattern similar to that of BMP-7 (12). Expression of twisted gastrulation was also detected in some distal tubules; however, the intensity of the signal was much lower than that of USAG-1, in accordance with the results of real-time PCR. Differential screening-selected gene aberrative in neuroblastoma (DAN) and protein related to DAN and Cerberus (PDRC) were faintly observed in the inner medulla, and other BMP antagonists were not detected with this method. 

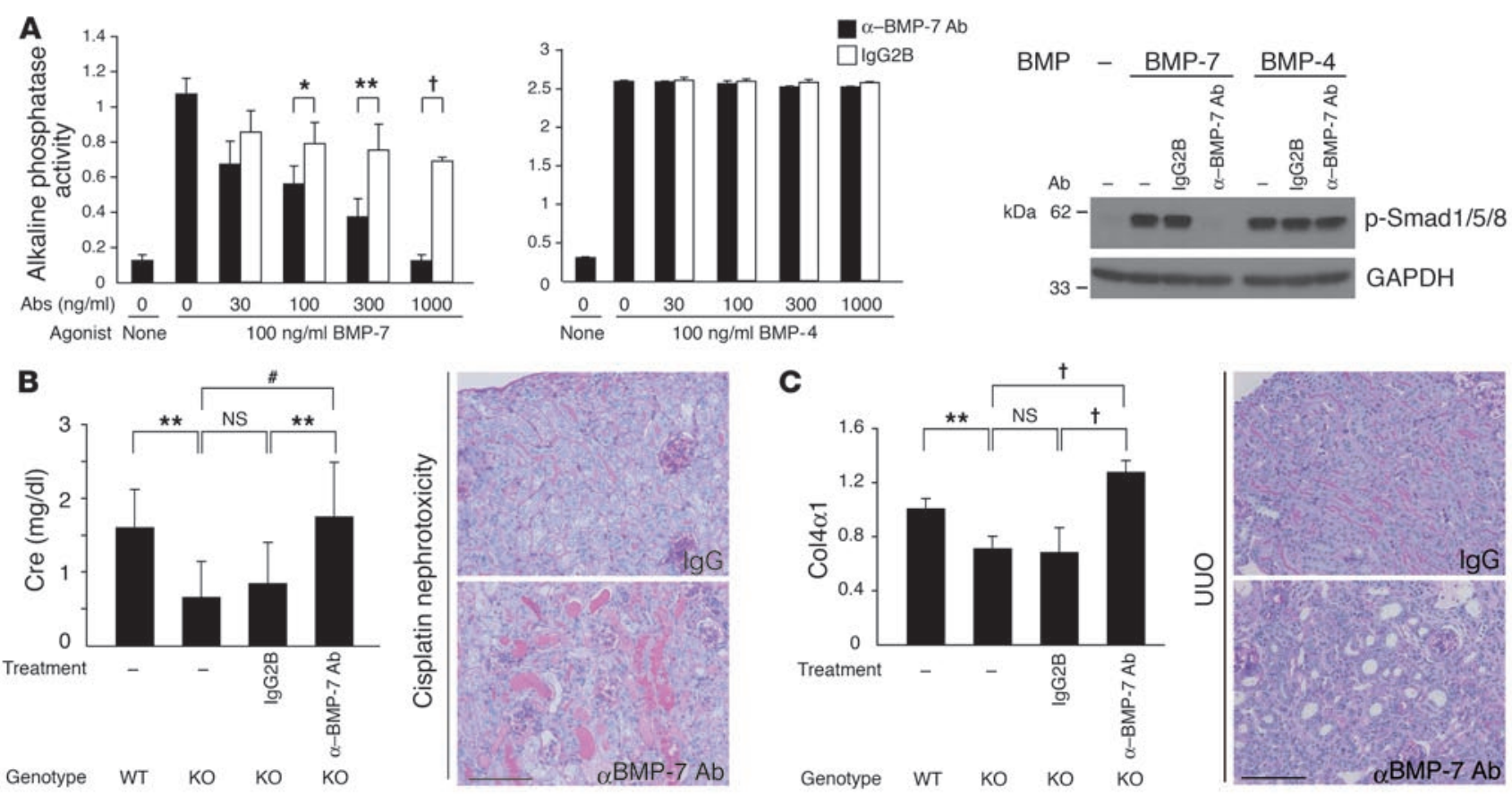

Figure 5

Blocking BMP-7 activity abolishes renoprotection in USAG1-/- mice. (A) Evaluation of neutralizing activity of anti-BMP-7 antibody. Anti-BMP-7 antibody inhibits alkaline phosphatase activity and phosphorylation of Smad1/5/8 induced by BMP-7, but not by BMP-4. (B) Serum creatinine level of USAG1-/- mice treated with anti-BMP-7 antibody and representative histological findings on day 3 of cisplatin nephrotoxicity. Scale bar: $100 \mu \mathrm{m}$. (C) Gene expression of type IV collagen in kidneys of USAG1-/- mice treated with anti-BMP-7 antibody and representative histological findings on day 14 of UUO. ${ }^{*} P<0.1 ;{ }^{*} P<0.01 ;{ }^{\#} P<0.001 ;{ }^{\dagger} P<0.0001$.

\section{Discussion}

Epithelial-mesenchymal transition (EMT) is a necessary step for renal fibrosis, as well as in embryonic development and tumor progression (29-31). TGF- $\beta$ is known to stimulate EMT, while BMP-7 inhibits and reverses the transition (3). Zeisberg et al. recently reported that BMP-7 reverses TGF- $\beta 1$-induced EMT and induces mesenchymal-epithelial transition in vitro $(4,32)$. They further demonstrated that administration of a pharmacological dose of BMP-7 resulted in regression of established lesions in the kidney and improved renal function. In this report, we demonstrated that deficiency of USAG-1, a novel BMP antagonist in the kidney, results in marked preservation of renal function by reinforcement of BMP signaling.

Based on these findings, we set the working hypothesis: in many types of renal disease, proximal tubule epithelial cells (PTECs) are the main site of injury (33) and undergo EMT, which causes loss of structural integrity of epithelial cells characterized by a reduction of E-cadherin expression and the induction of $\alpha$-SMA in interstitial myofibroblasts (Figure 7A). BMP-7 secreted from distal tubules (12) inhibits EMT of PTECs and induces redifferentiation of mesenchymal cells to epithelial cells. USAG-1 produced from distal tubules binds to BMP-7 and inhibits its renoprotective action by interfering with binding to its receptors.

In addition to the inhibition of EMT, many other pharmacological actions of BMP-7 have been reported. Administration of recombinant BMP-7 inhibits the induction of inflammatory cytokine expression in the kidney (12), attenuates inflammatory cell infiltration (6), and reduces apoptosis of tubular epithelial cells in renal disease models (34) (Figure 7A). These phenomena are also observed in $U S A G 1^{-/-}$mice, and the similarity between BMP-7-treated animals and USAG1 $1^{-/-}$mice strongly supports our working model that deficiency of USAG-1 reinforces the renoprotective activities of BMP.

In accordance with this hypothesis, the renoprotection in USAG1 $1^{-/-}$mice was abolished in both renal disease models when a neutralizing antibody against BMP-7 was administered (Figure 5). These results strongly support the hypothesis, and BMP-7 is a potent candidate for the counterpart of USAG-1.

We also observed preserved phosphorylation of Smad1/5/8 in the kidneys of USAG1/-- mice in both renal disease models, suggesting that BMP signaling was enhanced in USAG1-/- mice, while no difference was observed between WT and KO mice in phosphorylation of Smad1/5/8 prior to disease induction (Figure $4, \mathrm{~A}$ and $\mathrm{C}$ ). We assume that BMP signaling prior to disease induction might be potent enough to cause full phosphorylation of Smad1/5/8 regardless of the presence or absence of USAG-1, while in the later stages of kidney diseases, BMP signaling is decreased and the presence of USAG-1 might cause a further reduction in BMP signaling.

Furthermore, we demonstrated that USAG-1 is by far the most abundant BMP antagonist in the kidney (Figure 6A). Because other BMP antagonists also antagonize BMP-7 activities (Supplemental Figure 2), we conclude that USAG-1 plays an important role in the modulation of BMP activities in the kidney not because of its ligand specificity, but because of its high expression among other BMP antagonists. In addition, the tissue localization of USAG-1 (Figure 6B) is quite similar to that of BMP-7 (12), and USAG-1 can effectively access and inactivate BMP-7 at the site of production. 
A
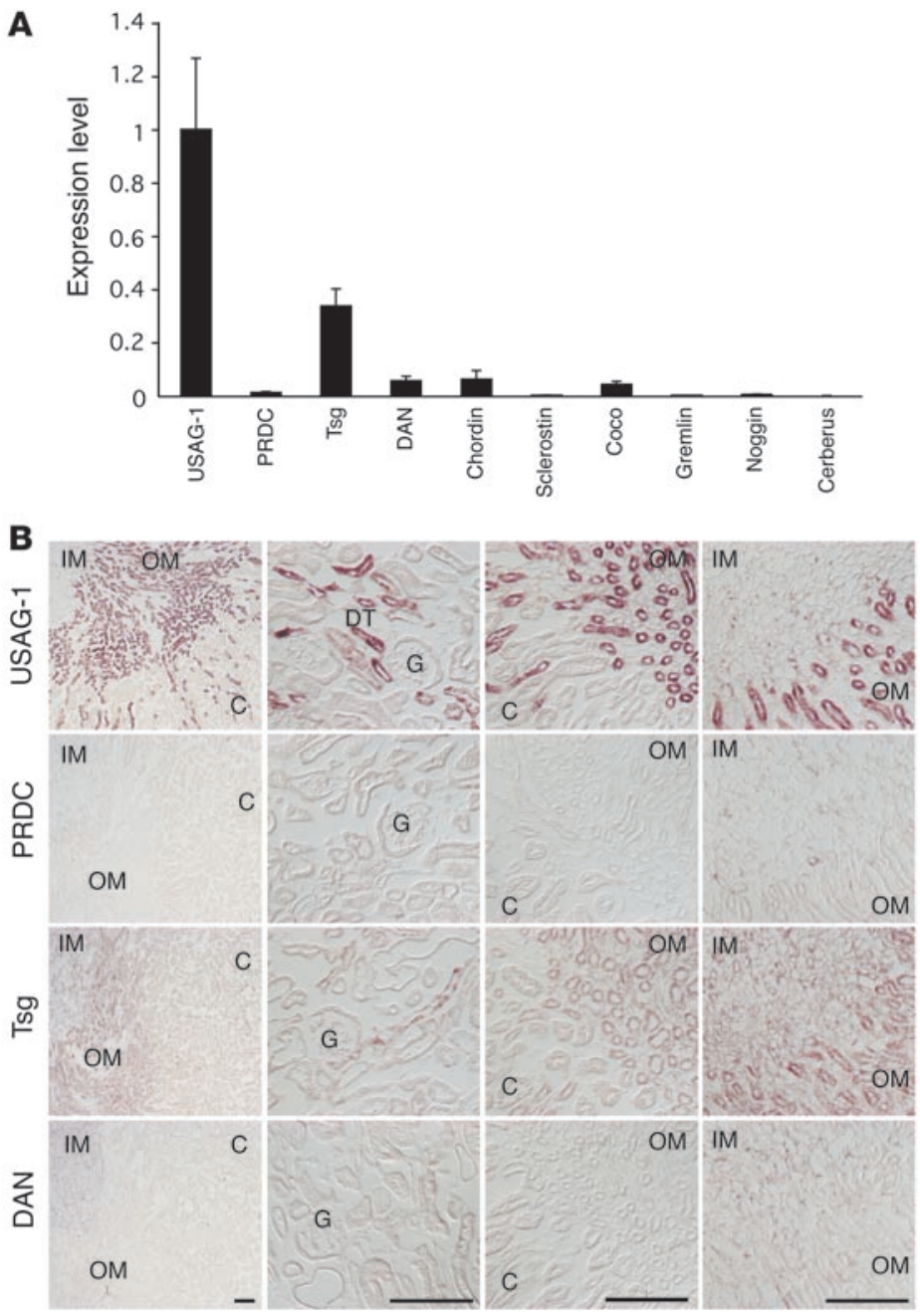

\section{Figure 6}

Expression of BMP antagonists in kidney. (A) Kidney cDNA of wild-type mice with Svj background was subjected to realtime PCR with various primers for BMP antagonists, and the standard curve was set using the plasmid encoding each BMP antagonist from concentrations of $1 \mathrm{pg} / \mu \mathrm{l}$ to $1 \mathrm{fg} / \mu \mathrm{l}$. The values of each BMP antagonist in the kidney cDNA were multiplied by the length of the vectors and normalized to the value of USAG-1 expression $(n=4-5)$. Expression of USAG-1 was by far the most abundant in the kidney among other BMP antagonists. Tsg, twisted gastrulation. (B) Kidney sections were subjected to in situ hybridization with probes for all BMP antagonists. Expression of USAG-1 was confined to the distal tubular epithelial cells. Twisted gastrulation was also sparsely expressed in some distal tubules. Differential screening-selected gene aberrative in neuroblastoma (DAN) and protein related to DAN and Cerberus (PDRC) were faintly detected in the inner medulla. Expression of other BMP antagonists was not detected by this method. Scale bars: $100 \mu \mathrm{m}$. IM, inner medulla; OM, outer medulla; C, cortex; DT, distal tubule; G, glomerulus.

effects, such as actions on renal osteodystrophy (35-39) and vascular calcification $(40,41)$.

Furthermore, these therapies targeted toward USAG-1 might protect the kidney during administration of nephrotoxic agents such as cisplatin. The pathological roles of USAG-1 in glomerular injury should be further elucidated before we undertake therapeutic trials against USAG-1.

Despite the essential role of BMP-7 in renal development, we did not observe any developmental abnormality in the kidney of USAG1 $1^{-1-}$ mice with this genetic background. We assume that there are many reasons for the lack of developmental abnormality: First, USAG-1 expression in the developing kidney is not apparent on embryonic day 11.5 (21), whereas BMP-7 expression is intense in the metanephric mesenchyme (42) with a pattern similar to that of gremlin (43). In the later stages, USAG-1 expression appears in the Although we illustrated USAG-1/BMP-7 binding as occurring outside of PTECs in Figure 7A, it might be possible that the binding occurs intracellularly within the secretory pathway in PTECs and that USAG-1 and BMP-7 are secreted in complex form. Further investigations are necessary to clarify this point.

Interestingly, the expression of USAG-1 decreased during the course of disease models (Supplemental Figure 3 and unpublished observations). We assume that the reduction of USAG-1 in renal diseases is a self-defense mechanism to minimize its inhibitory effect on BMP signaling. Because the reduction in USAG-1 expression in WT mice is not enough to overcome the reduction in BMP-7 expression, further reduction or abolishment of the action of USAG- 1 is desirable for the preservation of renal function, and the results of the present study justify therapy targeted toward USAG-1. For example, drugs or neutralizing antibodies that inhibit binding between USAG-1 and BMP or gene-silencing therapy for USAG1 would enhance the activity of endogenous BMP and might be a promising way to develop novel therapeutic methods for severe renal disease (Figure 7B). Because the expression of USAG-1 is confined to the kidney in adult mice and humans (21), it would be a better target for kidney-specific therapeutic trials. On the other hand, administration of recombinant BMP-7, whose target cells are widely distributed throughout the body, might produce some additional extrarenal actions, including beneficial tubular epithelium in the medullary region (21), whereas BMP-7 expression is confined to the condensed mesenchyme and peripheral ureteric epithelium (42). Therefore, the expression pattern of USAG-1 in the developing kidney is totally different from that of BMP-7. Second, the expression of USAG-1 is very low in early embryogenesis, increases toward the late stage of embryogenesis, and is much higher in the adult kidney (21), while the expression of gremlin is high in early embryogenesis with a pattern similar to that of BMP-7, and becomes almost undetectable in the healthy adult kidney (Figure 6). Furthermore, gremlin-deficient mice show severe developmental abnormality in the kidney, which is quite similar to that of BMP-7-deficient mice. Therefore, we conclude that gremlin is a regulator of BMP-7 activity in the developing kidney, and lack of USAG-1 might be compensated by gremlin and does not cause any developmental abnormality in the kidney.

Recently another function of USAG-1 as a modulator of Wnt signaling has been reported in Xenopus embryogenesis (44). Although the role of the Wnt pathway in the progression of renal diseases remains to be elucidated, there is a possibility that modulation of the Wnt pathway might also play some roles in the preservation of renal function in USAG1 $1^{-/-}$mice. Close relationships between the Wht and BMP pathways have also been reported; for instance, dickkopf homolog 1 (DKK1), a Wnt antagonist, and noggin, a BMP antagonist, cooperate in head induction, while the expression of 
A

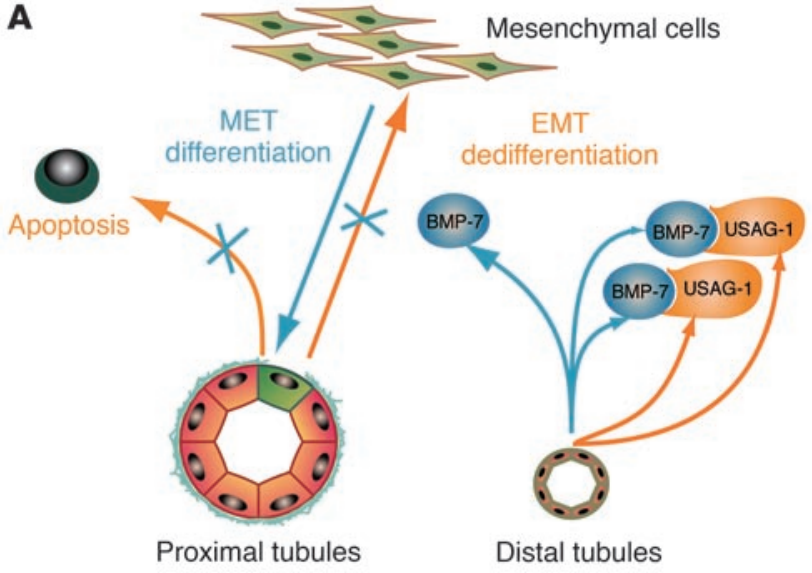

B

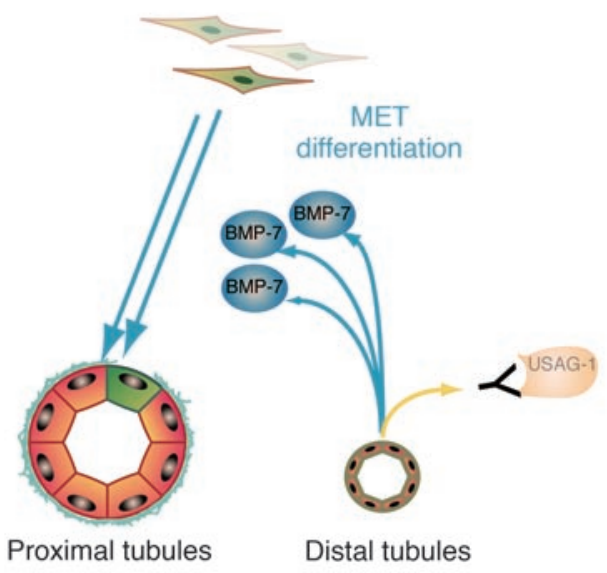

Figure 7

Working model of role of BMP-7 and USAG-1 in renal diseases. (A) In renal injury, PTECs are mainly damaged and undergo EMT to fibroblastlike mesenchymal cells. BMP-7 secreted by the distal tubule inhibits EMT and apoptosis of PTECs. USAG-1 is also secreted by the distal tubule, binds to BMP-7, and inhibits the renoprotective actions of BMP-7. (B) Therapeutic implication of USAG-1. Reduction of USAG-1 activity, for example, by a neutralizing antibody blocking the binding of USAG-1 and BMP-7, results in reinforcement of the renoprotective action of BMP-7. MET, mesenchymal-epithelial transition.

DKK1 is regulated by BMP-4 in limb development. Furthermore, a BMP antagonist, cerberus, has binding sites for both Wnt and BMP and antagonizes the activities of both the Wnt and BMP signaling pathways. USAG-1 might also have dual activities and act as a molecular link between these 2 important signaling pathways.

In conclusion, this study showed that USAG-1 plays important roles in the progression of renal diseases and might be a potent negative regulator of the renoprotective action of endogenous BMP signaling. Recently, Lin et al. identified a positive regulator of BMP-7 named kielin/chordin-like protein (KCP) and demonstrated that $\mathrm{KCP}^{-/-}$mice are susceptible to tubular injury and interstitial fibrosis (45). These data support the idea that BMP-7 protects the kidney from renal injury. Because these negative and positive modulators of BMP signaling regulate and edge the boundaries of BMP activity, further understanding of these modulators would give valuable information about their pathophysiological functions and provide a rationale for a therapeutic approach against these proteins.

\section{Methods}

Generation of USAG1 $1^{-/-}$mice. We isolated a genomic fragment containing the mouse USAG1 gene by screening a $129 /$ SvJ genomic library (Stratagene). We inserted an $\mathrm{nlacZ}$ gene and a PGK-NeoR cassette in the opposite transcriptional orientation to the USAG1 gene. ES cells were transfected with the linearized targeting vector by electroporation and selected by G418-containing medium. Homologous recombinants were screened and identified by genomic Southern blot analysis with an HincII-EcoRI probe mapping outside the $5^{\prime}$ homology arm (Figure 1A). Homologous recombined ES cell clones were obtained, and correct recombination was confirmed by Southern blot (Figure 1B) as well as PCR analyses. ES cells carrying the USAG1-null allele were injected into C57BL/6 blastocysts to obtain chimeric mice, which were crossed with wild-type C57BL/6J mice. Following germline transmission, the mice were maintained in a mixed SvJ background. PCR genotyping was used for all subsequent studies to allow specific detection of both the wildtype and USAG1 $1^{-/-}$alleles (Figure 1C). Sequences of the primers used for genotyping are as follows: F1, CCCCTCCTCATCTGGCTGCTTCCTAAACGG; R1, CAGTCACGACGTTGTAAAACGACGGGATCC; F2, GGGATCCCACCCCTTCTCT; and R2, GCCGGGACAGGTTTAACCA.

Animal use. All experiments except those represented in Supplemental Figure 3 were performed using $U S A G 1^{-/-}$mice and their wild-type littermates $\left(U S A G 1^{+/+}\right)$of the $\mathrm{F}_{2}$ generation. All mice were housed in specific pathogen-
Table 1

Primers for real-time RT-PCR

\begin{tabular}{|c|c|}
\hline Gene & Sequence of primers $\left(5^{\prime}-3^{\prime}\right)$ \\
\hline GAPDH & CCAGAACATCATCCCTGCATC; CCTGCTTCACCACCTTCTTGA \\
\hline$T N F \alpha$ & ATGAGAAGTTCCCAAATGGCC; CCTCCACTTGGTGGTTTGCTA \\
\hline$I L-1 \beta$ & CCTTCCAGGATGAGGACATGA; AACGTCACACACCAGCAGGTT \\
\hline TGF $\beta 1$ & GCAACAATTCCTGGCGTTACC; CGAAAGCCCTGTATTCCGTCT \\
\hline MCP-1 & TGCATCTGCCCTAAGGTCTTC; AAGTGCTTGAGGTGGTTGTGG \\
\hline Col4a1 & TTCCTTCGTGATGCACACCA; TTCTCATGCACACTTGGCAGC \\
\hline USAG1 & GCAACAGCACCCTGAATCAAG; TGTATTTGGTGGACCGCAGTT \\
\hline Chordin & GCAGTGGTTCCCAGAGAATCA; AACAATCGTCCCGCTCACAGT \\
\hline$D A N$ & CTTCAGTTACAGCGTCCCCAA; CCAAGGTCACAATCTCCCACA \\
\hline PRDC & AGGAGGCTTCCATCTCGTCAT; CCGGTTCTTCCGTGTTTCA \\
\hline Twisted gastrulation & AAACGTGTCTGTTCCCAGCAA; ACACTGGTGGATGGACATGCA \\
\hline Gremlin & AGCCCAAGAAGTTCACCACCA; TATGCAACGGCACTGCTTCAC \\
\hline Sclerostin & CAAGCCTTCAGGAATGATGCC; TCGGACACATCTTTGGCGT \\
\hline Noggin & AGAAACAGCGCCTGAGCAAGA; AAAAGCGGCTGCCTAGGTCAT \\
\hline Cerberus & CCCATCAAAAGCCACGAAGT; CCAAAGCAAAGGTTGTTCTGG \\
\hline Coco & TCCGCTTTTAGCCACTAGGTG; GCTGTTATTCTGGTGTCCCCA \\
\hline$B M P-2$ & TCGACCATGGTGGCCGGGACCCG; TGTTCCCGGAAGATCTGGAGT \\
\hline$B M P-3$ & AGCGAATGGATTATCTCTCCCA; TCTTTTCCGGCACACAGCA \\
\hline$B M P-4$ & CTGGAATGATTGGATTGTGGC; GCATGGTTGGTTGAGTTGAGG \\
\hline BMP-5 & AAGCCTGCAAGAAGCACGAA; GGAAAAGAACATTCCCCGTCA \\
\hline$B M P-6$ & CCAACCACGCCATTGTACAGA; GGAATCCAAGGCAGAACCATG \\
\hline$B M P-7$ & TGTGGCAGAAAACAGCAGCA; TCAGGTGCAATGATCCAGTCC \\
\hline
\end{tabular}


free conditions. Experiments represented in Supplemental Figure 3 were performed using C57BL/6 mice. All animal experiments were approved by the Animal Research Committee at the Graduate School of Medicine, Kyoto University, and the Animal Experiment and Use Committee at the University of Tsukuba and were in accordance with NIH guidelines.

Cisplatin administration. Cisplatin (Sigma-Aldrich) was administered at $20 \mathrm{mg} / \mathrm{kg}$ to mice by a single intraperitoneal injection. Mice were sacrificed 72 hours after administration of cisplatin, and tissue and blood were collected for further analysis.

UUO. Complete UUO was performed as previously described (46). Briefly, under sodium pentobarbital anesthesia, the middle portion of the left ureter was ligated and cut between 2 ligated points. At 14 days after surgery, the mice were sacrificed, and the obstructed kidneys were subjected to the studies described below.

Histological studies. The kidneys were fixed in Carnoy solution and embedded in paraffin. Sections $(2 \mu \mathrm{m})$ were stained with PAS for routine histological examination, and the degree of morphological changes was determined using light microscopy. The following parameters were chosen as indicative of morphological damage to the kidney after cisplatin injection and UUO: brush border loss, tubule dilatation, tubule degeneration, and tubule necrosis. These parameters were evaluated on a scale of 0 to 4 , and classed as: 0 , not present; 1 , mild; 2 , moderate; 3 , severe; and 4 , very severe. The remaining kidney was used for immunohistochemical study, RNA isolation, and protein extraction.

Immunostaining. Frozen sections of kidneys were subjected to immunostaining with polyclonal antibodies against type IV collagen (ICN Pharmaceuticals), phosphorylated Smad1/5/8 (Cell Signaling Technology), and phosphorylated Smad2/3 (Santa Cruz Biotechnology Inc.) and monoclonal antibodies against $\alpha$-SMA (Sigma-Aldrich) and Mac-1 (BD Biosciences - Pharmingen) as previously described $(47,48)$.

Immunoblotting. Whole kidney protein was homogenized in RIPA buffer (50 mM Tris at pH 7.5, $150 \mathrm{mM} \mathrm{NaCl}, 1 \%$ Nonidet P-40, 0.25\% SDS, $1 \mathrm{mM}$ $\mathrm{Na}_{3} \mathrm{VO}_{4}, 2 \mathrm{mM}$ EDTA, $1 \mathrm{mM} \mathrm{PMSF}$, and $10 \mu \mathrm{g} / \mathrm{ml}$ aprotinin) and subjected to immunoblotting as described previously (49). Anti-E-cadherin antibody and anti-GAPDH antibody were from BD Biosciences - Transduction Laboratories and Research Diagnostic Inc., respectively.

Apoptosis detection and quantification. The TUNEL technique (In Situ Cell Death Detection Kit; Roche Diagnostics GmbH) was used to detect apoptotic cells in situ. All apoptotic nuclei within a transverse section at the renal pelvis were counted.

Quantification of $m R N A$ by real-time RT-PCR. Real-time RT-PCR was performed with a 7700 Sequence Detection System (Applied Biosystems). Five micrograms of total RNA was reverse transcribed in a reaction volume of $20 \mu \mathrm{l}$ using Superscript III reverse transcriptase and random primers (Invitrogen Corp.). The product was diluted to a volume of $400 \mu \mathrm{l}$, and $5-\mu \mathrm{l}$ aliquots were used as templates for amplification using SYBR Green PCR amplification reagent (Applied Biosystems) and gene-specific primers. Specific primers for each gene transcript (listed in Table 1) were designed using Primer Express software version 2.0.0 (Applied Biosystems) and checked as to whether they showed a single peak in the dissociation curve. Serially diluted cDNA or plasmids encoding probes for in situ hybridization were used to generate the standard curve for each primer, and the PCR condi- tions were as follows: $50^{\circ} \mathrm{C}$ for 2 minutes, $95^{\circ} \mathrm{C}$ for 10 minutes, then $95^{\circ} \mathrm{C}$ for 15 seconds and $60^{\circ} \mathrm{C}$ for 1 minute for 40 cycles.

Administration of neutralizing antibody against BMP-7. In cisplatin nephrotoxicity, $1.5 \mathrm{mg} / \mathrm{kg}$ neutralizing anti-BMP-7 antibody (R\&D Systems Inc.) was peritoneally injected into $U S A G 1^{-1-}$ mice 24 hours after injection of cisplatin. In UUO, $0.5 \mathrm{mg} / \mathrm{kg}$ neutralizing anti-BMP-7 antibody was injected every 3 days from day 2 to day 11. As a negative control, isotype-matched IgG2B (BD Biosciences) was injected at the same time points. Neutralizing activity of the antibody was evaluated by an assay measuring the production of alkaline phosphatase activity by C2C12 cells, as previously described (21).

In situ bybridization. The kidneys were excised from adult male mice and fixed in $4 \%$ paraformaldehyde in PBS. Frozen sections ( $5 \mu \mathrm{m}$ thick) were treated with $1 \mu \mathrm{g} / \mathrm{ml}$ proteinase $\mathrm{K}$ in PBS at $37^{\circ} \mathrm{C}$ for 30 minutes and acetylated in $0.1 \mathrm{M}$ triethanolamine- $\mathrm{HCl}, 0.25 \%$ acetic anhydride for $15 \mathrm{~min}$ utes. Hybridization was performed with probes at concentrations of about $1 \mu \mathrm{g} / \mathrm{ml}$ in a hybridization solution ( $50 \%$ formamide, $\times 5$ SSC, $1 \%$ SDS, 50 $\mu \mathrm{g} / \mathrm{ml}$ transfer RNA, and $50 \mu \mathrm{g} / \mathrm{ml}$ heparin) at $60^{\circ} \mathrm{C}$ for 16 hours. RNA probes were synthesized by in vitro transcription with a DIG RNA Labeling Mix (Roche Diagnostics Corp.). Each probe was designed to contain an open reading frame with the following length and $\mathrm{G}+\mathrm{C}$ content: USAG-1, $1.0 \mathrm{kbp}(\mathrm{G}+\mathrm{C}$ 52.6\%); sclerostin, $1.5 \mathrm{kbp}$ (61.7\%); coco, $1.2 \mathrm{kbp}(54.7 \%)$; DAN, $1.0 \mathrm{kbp}$ (60.6\%); twisted gastrulation, $0.7 \mathrm{kbp}$ (55.1\%); PRDC, 0.8 $\mathrm{kbp}$ (57.7\%); chordin, $1.5 \mathrm{kbp}$ (60.2\%); gremlin, $0.9 \mathrm{kbp}$ (50\%); noggin, 0.7 $\mathrm{kbp}$ (64.7\%); cerberus, $1.5 \mathrm{kbp}$ (48.8\%). Hybridization was detected using an anti-DIG AP conjugate (Roche Diagnostic Corp.) and NBT/BCIP solution (Roche Diagnostics Corp.).

Analysis of phenotype of adult teeth. Skeletal preparations of the maxillae and mandibles were made by soaking the mouse heads in $0.02 \%$ proteinase $\mathrm{K}$ in PBS at $37^{\circ} \mathrm{C}$ for 4 days after peeling off the skin, dissecting the maxillae and mandibles, and clearing them in $5 \% \mathrm{H}_{2} \mathrm{O}_{2}$ at room temperature for 5 minutes. Finally they were rinsed in $\mathrm{H}_{2} \mathrm{O}$ and left to dry.

Statistics. All assays were performed in triplicate. Data are presented as mean \pm SD. Statistical significance was assessed by ANOVA, followed by Fisher's protected least significant difference post-hoc test. Survival curves were derived using the Kaplan-Meier method and compared using log-rank test.

\section{Acknowledgments}

We are grateful to Y. Nabeshima, T. Nakahata, and T. Nakamura for helpful discussion. We are grateful to M. Yoshimoto for hematological evaluation of the mice. We thank A. Godo, H. Uchiyama, and A. Hosoya for technical assistance. We thank W. Gray for reading the manuscript.

Received for publication April 25, 2005, and accepted in revised form October 11, 2005.

Address correspondence to: Motoko Yanagita, COE Formation for Genomic Analysis of Disease Model Animals with Multiple Genetic Alterations, Graduate School of Medicine, Kyoto University, Shogoin Kawahara-cho 54, Kyoto 606-8507, Japan. Phone: 81-75-7513465; Fax: 81-75-751-3574; E-mail: motoy@kuhp.kyoto-u.ac.jp.
1. Eddy, A.A. 1996. Molecular insights into renal interstitial fibrosis. J. Am. Soc. Nephrol. 7:2495-2508.

2. van Kooten, C., Daha, M.R., and van Es, L.A. 1999. Tubular epithelial cells: a critical cell type in the regulation of renal inflammatory processes. Exp. Nephrol. 7:429-437.

3. Neilson, E.G. 2005. Setting a trap for tissue fibrosis. Nat. Med. 11:373-374.

4. Zeisberg, M., et al. 2003. BMP-7 counteracts TGF- beta1-induced epithelial-to-mesenchymal transition and reverses chronic renal injury. Nat. Med. 9:964-968.

5. Vukicevic, S., et al. 1998. Osteogenic protein-1 (bone morphogenetic protein-7) reduces severity of injury after ischemic acute renal failure in rat. J. Clin. Invest. 102:202-214.

6. Hruska, K.A., et al. 2000. Osteogenic protein-1 prevents renal fibrogenesis associated with ure- teral obstruction. Am. J. Physiol. Renal. Physiol. 279:F130-F143.

7. Hruska, K.A. 2002. Treatment of chronic tubulointerstitial disease: a new concept. Kidney Int. 61:1911-1922.

8. Zeisberg, M., et al. 2003. Bone morphogenic protein-7 inhibits progression of chronic renal fibrosis associated with two genetic mouse models. Am. J. Physiol. Renal. Physiol. 285:F1060-F1067. 
9. Dudley, A.T., Lyons, K.M., and Robertson, E.J. 1995. A requirement for bone morphogenetic protein-7 during development of the mammalian kidney and eye. Genes Dev. 9:2795-2807.

10. Luo, G., et al. 1995. BMP-7 is an inducer of nephrogenesis, and is also required for eye development and skeletal patterning. Genes Dev. 9:2808-2820.

11. Ozkaynak, E., et al. 1990. OP-1 cDNA encodes an osteogenic protein in the TGF-beta family. EMBOJ. 9:2085-2093.

12. Gould, S.E., Day, M., Jones, S.S., and Dorai, H. 2002. BMP-7 regulates chemokine, cytokine, and hemodynamic gene expression in proximal tubule cells. Kidney Int. 61:51-60.

13. Simon, M., et al. 1999. Expression of bone morphogenetic protein-7 mRNA in normal and ischemic adult rat kidney. Am. J. Physiol. 276:F382-F389.

14. Wang, S.N., Lapage, J., and Hirschberg, R. 2001. Loss of tubular bone morphogenetic protein-7 in diabetic nephropathy. J. Am. Soc. Nephrol. 12:2392-2399.

15. Lund, R.J., Davies, M.R., and Hruska, K.A. 2002. Bone morphogenetic protein-7: an anti-fibrotic morphogenetic protein with therapeutic importance in renal disease. Curr. Opin. Nephrol. Hypertens. 11:31-36.

16. Almanzar, M.M., et al. 1998. Osteogenic protein-1 mRNA expression is selectively modulated after acute ischemic renal injury. J. Am. Soc. Nephrol. 9:1456-1463.

17. Massague, J., and Chen, Y.G. 2000. Controlling TGF-beta signaling. Genes Dev. 14:627-644.

18. Simmons, D.G., and Kennedy, T.G. 2002. Uterine sensitization-associated gene-1: a novel gene induced within the rat endometrium at the time of uterine receptivity/sensitization for the decidual cell reaction. Biol. Reprod. 67:1638-1645.

19. Avsian-Kretchmer, O., and Hsueh, A.J. 2004. Comparative genomic analysis of the eight-membered ring cystine knot-containing bone morphogenetic protein antagonists. Mol. Endocrinol. 18:1-12.

20. Laurikkala, J., Kassai, Y., Pakkasjarvi, L., Thesleff, I., and Itoh, N. 2003. Identification of a secreted BMP antagonist, ectodin, integrating BMP, FGF, and $\mathrm{SHH}$ signals from the tooth enamel knot. Dev. Biol. 264:91-105.

21. Yanagita, M., et al. 2004. USAG1: a bone morphogenetic protein antagonist abundantly expressed in the kidney. Biochem. Biophys. Res. Commun. 316:490-500.

22. Schrier, R.W. 2002. Cancer therapy and renal injury. J. Clin. Invest. 110:743-745. doi:10.1172/ JCI200216568.
23. Megyesi, J., Safirstein, R.L., and Price, P.M. 1998. Induction of p21WAF1/CIP1/SDI 1 in kidney tubule cells affects the course of cisplatin-induced acute renal failure. J. Clin. Invest. 101:777-782.

24. Ramesh, G., and Reeves, W.B. 2002. TNF- $\alpha$ mediates chemokine and cytokine expression and renal injury in cisplatin nephrotoxicity. J. Clin. Invest. 110:835-842. doi:10.1172/JCI200215606.

25. Yang, J., and Liu, Y. 2001. Dissection of key events in tubular epithelial to myofibroblast transition and its implications in renal interstitial fibrosis. Am. J. Pathol. 159:1465-1475.

26. Klahr, S., and Morrissey, J. 2002. Obstructive nephropathy and renal fibrosis. Am. J. Physiol. Renal. Physiol. 283:F861-F875.

27. Chevalier, R.L. 1999. Molecular and cellular pathophysiology of obstructive nephropathy. Pediatr. Nephrol. 13:612-619.

28. Sato, M., Muragaki, Y., Saika, S., Roberts, A.B., and Ooshima, A. 2003. Targeted disruption of TGFbeta1/Smad3 signaling protects against renal tubulointerstitial fibrosis induced by unilateral ureteral obstruction. J. Clin. Invest. 112:1486-1494. doi:10.1172/JCI200319270.

29. Kalluri, R., and Neilson, E.G. 2003. Epithelialmesenchymal transition and its implications for fibrosis. J. Clin. Invest. 112:1776-1784. doi:10.1172/ JCI200320530.

30. Bottinger, E.P., and Bitzer, M. 2002. TGF-beta signaling in renal disease. J. Am. Soc. Nephrol. 13:2600-2610.

31. Iwano, M., et al. 2002. Evidence that fibroblasts derive from epithelium during tissue fibrosis. J. Clin. Invest. 110:341-350. doi:10.1172/JCI200215518.

32. Zeisberg, M., Shah, A.A., and Kalluri, R. 2005. Bone morphogenic protein-7 induces mesenchymal to epithelial transition in adult renal fibroblasts and facilitates regeneration of injured kidney. J. Biol. Chem. 280:8094-8100.

33. Gerritsma, J.S., van Kooten, C., Gerritsen, A.F., van Es, L.A., and Daha, M.R. 1998. Transforming growth factor-beta 1 regulates chemokine and complement production by human proximal tubular epithelial cells. Kidney Int. 53:609-616.

34. Li, T., Surendran, K., Zawaideh, M.A., Mathew, S., and Hruska, K.A. 2004. Bone morphogenetic protein 7: a novel treatment for chronic renal and bone disease. Curr. Opin. Nephrol. Hypertens. 13:417-422.

35. Davies, M.R., Lund, R.J., Mathew, S., and Hruska, K.A. 2005. Low turnover osteodystrophy and vascular calcification are amenable to skeletal anabo- lism in an animal model of chronic kidney disease and the metabolic syndrome. J. Am. Soc. Nephrol. 16:917-928.

36. Gonzalez, E.A., et al. 2002. Treatment of a murine model of high-turnover renal osteodystrophy by exogenous BMP-7. Kidney Int. 61:1322-1331.

37. Hruska, K.A., et al. 2004. Kidney-bone, bone-kidney, and cell-cell communications in renal osteodystrophy. Semin. Nephrol. 24:25-38.

38. Lund, R.J., Davies, M.R., Brown, A.J., and Hruska, K.A. 2004. Successful treatment of an adynamic bone disorder with bone morphogenetic protein-7 in a renal ablation model. J. Am. Soc. Nephrol. 15:359-369.

39. Simic, P., and Vukicevic, S. 2005. Bone morphogenetic proteins in development and homeostasis of kidney. Cytokine Growth Factor Rev. 16:299-308.

40. Davies, M.R., Lund, R.J., and Hruska, K.A. 2003. BMP-7 is an efficacious treatment of vascular calcification in a murine model of atherosclerosis and chronic renal failure. J. Am. Soc. Nephrol. 14:1559-1567.

41. Hruska, K.A., Mathew, S., and Saab, G. 2005. Bone morphogenetic proteins in vascular calcification. Circ. Res. 97:105-114.

42. Godin, R.E., Takaesu, N.T., Robertson, E.J., and Dudley, A.T. 1998. Regulation of BMP7 expression during kidney development. Development. 125:3473-3482.

43. Michos, O., et al. 2004. Gremlin-mediated BMP antagonism induces the epithelial-mesenchymal feedback signaling controlling metanephric kidney and limb organogenesis. Development. 131:3401-3410.

44. Itasaki, N., et al. 2003. Wise, a context-dependent activator and inhibitor of Wnt signalling. Development. 130:4295-4305.

45. Lin, J., et al. 2005. Kielin/chordin-like protein, a novel enhancer of BMP signaling, attenuates renal fibrotic disease. Nat. Med. 11:387-393.

46. Nishida, M., et al. 2002. Absence of angiotensin II type 1 receptor in bone marrow-derived cells is detrimental in the evolution of renal fibrosis. J. Clin. Invest. 110:1859-1868. doi:10.1172/JCI200215045.

47. Yanagita, M., et al. 2001. Gas6 regulates mesangial cell proliferation through Axl in experimental glomerulonephritis. Am. J. Pathol. 158:1423-1432.

48. Yanagita, M., et al. 2001. Gas6 induces mesangial cell proliferation via latent transcription factor STAT3. J. Biol. Chem. 276:42364-42369.

49. Yanagita, M., et al. 2002. Essential role of Gas 6 for glomerular injury in nephrotoxic nephritis. J. Clin. Invest. 110:239-246. doi:10.1172/JCI200214861. 